Please do not remove this page

RMIT

UNIVERSITY

\title{
Effects of recycled concrete aggregates on properties of asphalt concrete
}

Paranavithana, Sumeda; Mohajerani, Abbas

https://researchrepository.rmit.edu.au/esploro/outputs/9921862322201341/filesAndLinks?institution=61RMIT_INST\&index=null

Paranavithana, S., \& Mohajerani, A. (2006). Effects of recycled concrete aggregates on properties of asphalt concrete. Resources Conservation and Recycling, 48(1), 1-12.

https://doi.org/10.1016/j.resconrec.2005.12.009

Document Version: Accepted Manuscript

Published Version: https://doi.org/10.1016/j.resconrec.2005.12.009

Repository homepage: https://researchrepository.rmit.edu.au

(C) 2006 Elsevier B.V. All rights reserved.

Downloaded On 2023/04/26 21:35:20 +1000

Please do not remove this page 


\title{
EFFECTS OF RECYCLED CONCRETE AGGREGATES ON PROPERTIES OF ASPHALT CONCRETE
}

\author{
Sumeda Paranavithana \\ VicRoads, Australia
}

Abbas Mohajerani

School of Civil \& Chemical Engineering, RMIT University, GPO Box 2476V, Melbourne, Australia, 3001

* Corresponding author. Tel +613 9925 3082; Fax +613 96390138

E-mail address: dr.abbas@rmit.edu.au

Citation:

Paranavithana, S and Mohajerani, A 2006, 'Effects of recycled concrete aggregates on properties of asphalt concrete', Resources Conservation and Recycling, vol. 48, no. 1, pp. 112.

http://researchbank.rmit.edu.au/view/rmit:182 


\section{ABSTRACT}

Recycled concrete aggregates (RCA) are produced by crushing demolished concrete elements. RCA differ from fresh aggregates due to the cement paste attached to the surface of the original natural aggregates after the process of recycling. This highly porous cement paste and other contaminations contribute to the lower particle density and higher porosity, variation in the quality of the RCA and the higher water absorption. This paper presents some of the results of an investigation on the possible application of RCA in asphalt concrete. It was found that all the volumetric properties (except the percentage of air-voids), resilient modulus and creep values of asphalt specimens containing RCA as coarse aggregates were relatively lower compared with the values found for similar specimens made with only fresh aggregates. Some of these measured properties were within the acceptable recommended limits, for the RCA sample used in this study.

Keywords: Recycled concrete aggregates; recycled materials; Waste management; construction and demolition waste; Asphalt mix design; Pavement materials; crushed aggregates; Volumetric and mechanical properties

\section{INTRODUCTION}

With the growth in world population, the amount of waste generation is increasing at an alarming rate. This rate of waste increase is rapidly filling our remaining sites for future landfills, causing a blowout in the cost of waste disposal. To counter this trend, considerable effort is being put into recycling waste, turning it into re-usable by products.

Demolished concrete structures are proven to be a good source of construction material. RCA is produced by the process of crushing demolished concrete elements. RCA were initially used as a fill material and after many research works (e.g. Paul, 1994; Richardson and Jordan, 1994; Guithrie and Mallett, 1995; Roos and Zlich, 1998; Chini and Monteiro, 1999; Arm, 2001; McGrath, 2001; Huang et al., 2002; Mroueh and Wahlstram, 2002) it is now being utilised as road subbase material, and in non-structural concrete applications such as kerbs, driveways, footpaths etc.

RCA differ from fresh aggregates due to the amount of cement paste remaining on the surface of the original natural aggregates after the process of recycling. This highly porous cement paste contributes to the lower particle density and higher porosity, variation in the quality of the RCA and the higher water absorption. Also RCA is contaminated with glass, 
rubber, asphalt, bricks and other soft or friable particles (Ravindrarajah, 1996; Dumitru et al., 1996; Sagoe-Crentcil et al., 1996; Shayan et al., 1997; Arm, 2001; Gomez-Sobern, 2002, Chen et al., 2002, Zahariera et al., 2002). This paper presents some of the findings of an investigation of RCA on properties asphalt.

\section{MATERIALS AND METHODS}

The following asphalt mixes were prepared in this investigation.

Mix I: control mix containing fresh crushed basalt aggregates, 5.0\%, 5.5\% and 6.0\% bitumen

Mix II: $\quad(0-4.75 \mathrm{~mm})$ fresh aggregates and $(4.75-20 \mathrm{~mm}) \mathrm{RCA}, 5.1 \%, 5.5 \%, 6.0 \%$ and $6.5 \%$ bitumen

Figure 1 presents the particle size distribution of aggregates used for the preparation of Mix I and Mix II. Mix I contains only fresh aggregates and Mix II contains RCA as coarse aggregates. Fine sand and hydrated lime (filler passing $0.075 \mathrm{~mm}$ sieve) were added to achieve the required aggregate combinations. Specific gravity, water absorption, percent stripping and wet/dry strength variation were determined for the aggregates and the results are summerised in Tables 2 and 3.

To determine the results presented in Table 1 aggregates were first combined in pre-determined proportions to obtain the appropriate gradations and then separated in to coarse and fine fractions using $4.75 \mathrm{~mm}$ standard sieve. The coarse and fine fractions were then separately tested for density and water absorption. According to Australian Standard 1141.3.2-1992, RCA were tested for weak particles content; results are summerised in Table 3.

In order to study the effect of binder content on compacted asphalt containing RCA, Mix II was prepared with 5.1\%, 5.5\%, 6.0\% and 6.5\% bitumen contents. Also Mix I was prepared with fresh crushed basalt aggregates at 5.0\%, 5.5\% and 6.0\% bitumen contents as control mix. To study the effect of compactive effort on asphalt containing RCA, specimens were prepared from each mix using 80 and 120 number of gyrations in a Servopac gyratory compactor. This machine is capable of applying a vertical loading stress of $240 \mathrm{kPa}$ to a specimen in the mould at a rate of $60 \mathrm{rpm}$ at a total fixed gyratory angle set between $0^{\circ}$ and $3^{\circ}$ measured at the center of the height of the mould. The gyratory motion of the mould produces a shearing action in the material as it is compressed axially (AS 2891.2.2). The specimens produced for this investigation were of dimensions $150 \mathrm{~mm}$ diameter and $75 \mathrm{~mm}$ thick. Compaction temperature Was $150{ }^{\circ} \mathrm{C}$. 
An UTM-5P testing machine was employed to perform the resilient modulus and dynamic creep tests. The equipment is a closed-loop, fully automatically controlled data acquisition system capable of applying repeated dynamic loads through a shaft of a pneumatic actuator. For the resilient modulus test, the pulse width and pulse repetition period were set at $0.1 \mathrm{~s}$. and 3 s., respectively (AS 2891.13.1). Pulse width of $0.5 \mathrm{~s}$. and pulse repetition period of $2 \mathrm{~s}$. were used for the creep test (AS 2891.12.1). The specimens were mounted on the indirect tensile jig for the indirect tensile test (Figure 2) and in the creep jig for the creep test (Figure 3) which are capable of testing specimens of $150 \mathrm{~mm}$ diameter. The Resilient modulus test requires the measurement of horizontal deformation of the curved surface of the specimen and the creep test requires the measurement of vertical deformation. These deformations are measured using linear variable differential transducers (LVDT) mounted on the sample.

Bulk densities and maximum densities of asphalt specimens were determined according to relevant Australian Standards (AS 2891.9.2 and AS 2891.7.1). These values together with the corrected gradation of mixture containing RCA were used to calculate the volumetric properties of asphalt specimens.

\section{RESULTS AND DISCUSSION}

Table 1 presents the densities and water absorptions of combined aggregates used for Mix I and Mix II. The densities of coarse fractions in Mix II, containing RCA, were lower compared to that of control mix. When they were combined with fine aggregates, the combined densities became considerably higher. The water absorption of the coarse fraction in Mix II, containing RCA, was significantly higher and when it was combined with fine aggregates this value decreased from 5.9\% to 4\%. According to APRG report number 18 (APRG, 1998) the preferred limits for water absorption is 2 to $4 \%$.

Results presented in Table 2 show that stripping potential of RCA sample, used in this study, was significantly higher and exceeded the allowable limit of $10 \%$. Also, RCA was of greater variation in strengths under wet and dry conditions. This was due to the easy separation of the mortar attached to RCA under compression and crushing. Table 3 shows the percent of foreign material content in the RCA used in this study. These values are lower than the maximum limits specified by VicRoads (VicRoads, 1992) for class CC2 recycled concrete aggregates. 
Table 4 presents the physical and mechanical properties obtained for Mix II with different binder contents at two different levels of gyrations selected. The control mix, Mix I, properties are given in Table 5. These results are graphically presented in Figures 4 - 10.

It should be noted that a significant change in particle size distribution of aggregate mixtures containing RCA as coarse aggregates was observed before and after mechanical mixing and compaction. This was due to the breaking of relatively weak cement mortar attached onto RCA particles due to the effect of mixing and compaction. The volumetric properties given in Table 4 are based on a corrected aggregate gradation that could be expected after mixing and compaction. This issue will be addressed in detail in another paper.

Resilient modulus is a measure of the stiffness of a material. The higher the resilient modulus, higher the load carrying capacity is. As the name implies, the resilient modulus includes the recovered horizontal deformation in the calculations. According to the results obtained (Figure 4), the stiffness of the asphalt containing RCA decreases with the increase in binder content. Also the mixes have lower stiffness values compared to the control mix. The reason could be the addition of low strength mortar, attached to RCA particles, to the mix and the use of RCA in the mix. Also, as were expected, higher compaction level increases the resilient modulus and improves the load spreading capacity.

Permanent deformation characteristics of Mix I and II are shown in Figure 5. It can be seen that creep increases with the binder content and decreases with the increase in compactive effort. The mixes containing RCA behave similar to the conventional mixes in regarding to creep. These experiments were conducted at $50^{\circ} \mathrm{C}$ (assumed warmest in-service temperature). For the control mix creep test was conducted only for $5.0 \%$ bitumen and 80 gyrations. The determined value for minimum creep slope was $2.682 \mu \varepsilon /$ pulse, which was higher than those found for mixes containing RCA.

As seen in Figure 6, air voids decreases with the increase of binder content and also with the level of compaction. Air voids of mixes containing RCA are considerably higher than the control mix due to the highly porous cement mortar attached onto original aggregates. 
Bulk density also shows the typical relationship of having an optimum value (Figure 7). Higher effort of compaction increases the bulk density. Bulk densities of mixes containing RCA are significantly lower, mainly due to the low dense cement mortar, than those for mixes made with fresh aggregates (Mix I)

Figure 8 shows the variation of voids in mineral aggregates (VMA) with binder content for Mix I and Mix II. VMA increases with the binder content after having a minimum point. VMA is a direct function of air voids and effective binder. Higher level of compaction reduces the air voids, and hence the VMA reduces with the increase of the compactive effort. VMA of mixes containing RCA is relatively lower than the control mix due to the higher absorption of RCA and hence the lower amount of effective binder.

Figure 9 shows the variation of voids filled with bitumen (VFB) with the bitumen content and the compactive effort. VFB is the proportion of voids in the mineral aggregates that are filled with bitumen. Therefore it is the ratio between the volume of effective binder and the VMA. When the level of compaction increases, the total volume of air voids decreases, resulting a higher VFB. The values obtained for mixes made with RCA are comparatively lower to the control mix due to the higher degree of absorption, resulting in lesser amount of effective binder.

More binder is absorbed by the aggregates containing RCA and this reduces the binder available for coating the aggregate particles. Thus the film thickness values for Mix II are lower (Figure 10) compared to those for control mix (Mix I), for the same bitumen content. As expected, the binder film thickness increased with the increase in binder content.

\section{CONCLUSIONS}

This paper has presented some of the experimental results obtained in an investigation of the effect of recycled concrete aggregates (RCA) on the properties of asphalt. Properties of asphalt containing RCA as coarse aggregates and asphalt containing only fresh aggregates (control mix) were analysed. It was found that the bulk density, voids in mineral aggregates, voids filled with binder and film thickness in the compacted asphalt specimens, containing RCA, were lower than those for the control mix. And the air voids were higher for specimens containing RCA. 
The resilient modulus of asphalt containing RCA decreased with the increase in binder content and these values were significantly lower than the corresponding control mix values. This could be due to the addition of low strength mortar together with the use of relatively lower quality aggregates in the mix. However, those values were within the acceptable limits recommended by the Austroads Pavement Research Group. The resilient modulus increased with the increasing level of compaction.

The experimental results found for unbound RCA, used in this study, were compared with those found for fresh crushed basalt aggregates. Due to the highly porous, low dense cement mortar attached onto RCA particles, the particle densities of RCA were relatively much lower and the water absorptions of RCA were much higher. Stripping potential of RCA was found to be significantly higher and RCA samples tested were of greater variation in strengths under wet and dry conditions.

The results found in this study are encouraging, however, further investigation is required to examine the findings in this research using different samples of recycled concrete aggregates and to investigate the application of current mix design methods for asphalt mixtures containing RCA.

\section{ACKNOWLEDGMENT}

The results presented in this paper are part of a postgraduate research on utilisation of recycled concrete aggregates in asphalt concrete. The authors would like to thank Alex Fraser Recyclers, Boral (Delta) Pty ltd., Pioneer Asphalt Plant and BP bitumen for supplying of the materials required for this post graduate study. This paper was prepared and submitted for publication while the $1^{\text {st }}$ author was undertaking her postgraduate study at RMIT University.

\section{REFERENCES}

Arm, M. C., 2001. Self-cementing properties of crushed demolished concrete in unbound layers: results from triaxial tests and field tests. Waste management, 21: 235-239;

AS 1141. Methods for sampling and testing aggregates. Australian Standard, Standards Association of Australia, Australia. AS 2150. Hot mix asphalt, Australian Standard, Standards Association of Australia, Australia. 
AS 2758. Aggregates and rock for engineering purposes, Australian Standard, Standards Association of Australia, Australia.

AS 2891. Methods of sampling and testing asphalt. Australian Standard, Standards Association of Australia, Australia. APRG, 1998. Selection and design of asphalt mixes: Australian provisional guide, APRG Report No. 18, Austroads, Sydney.

Chen, H., yen, T.and Chen, K., 2002. Use of building rubbles as recycled aggregates: Cement and Concrete Research, 33: $125-132$.

Dumitru, I., Formosa, M.and Zdrilic, A., 1996. Manufacture of Base Material Using Recycled Concrete to comply with RTA (NSW) Specifications: Programme and Proceedings of the use of recycled materials in engineering constructions, The Institute of Engineers Australia, 30-31 May 1996, PP. 211-217.

Gomez-Sobern, J. M. V., 2002. Porosity of recycled concrete with substitution of recycled concrete aggregates: An experimental study, Cement and Concrete Research, 32: 1301-1311.

Guthrie, P.and Mallett, H., 1995. Waste minimization and recycling in construction, A review: special publication 122, Construction Industry Research and Information Association (CIRIA), London.

Huang, W., Lin, D., Chang, N and Song, K., 2002. Recycling of construction and demolition waste via a mechanical sorting process: Resources, Conservation and Recycling, 37: 23-37.

McGrath, C., 2001. Waste minimization in practice: Resource, Conservation and Recycling, 32: 227-238.

Mroueh, U.and Wahlstram, M., 2002. By-products and recycled materials in earth construction in Finland - an assessment of applicability: Resources, Conservation and Recycling, 35: 117-129.

Paul R., 1994. Use of Recycled Crushed Concrete for road pavement Sub-base, Workshop on Pavement Recycling Technology, 19-20 October 1994, Canberra.

Ravindrarajah, R. S., 1996. Effects of using recycled concrete aggregates on the Engineering Properties of Concrete: Programme and Proceedings of the use of recycled materials in Engineering constructions, The Institute of Engineers, Australia 30-31 May 1996, pp147-152.

Richardson, B. J. E. and Jordon, D. O., 1994. Use of recycled concrete as a road pavement material within Australia: Proceedings 17th ARRB conference, Part 3, pp 213-228.

Roos, F.and Zlich, K., 1998. Verification of the dimensioning values for concrete with recycling concrete aggregates: Symposium on sustainable construction and use of recycled concrete aggregates, 11-12 November 1998, London. 
Sagoe-Crentsil, K. K., Brown, T., Mak, S. L.and Taylor, A., 1996. Engineering Properties and Performance of Concrete Made with Recycled Construction Aggregates: Programme and Proceedings of the use of recycled materials in Engineering constructions, 30-31 May 1996, The Institute of Engineers, Australia, pp. 132-135.

Shayan, A., Bell, D. and Westgate, P., 1997. Performance of Recycled concrete as a Road-making Material: Municipal Engineering in Australia, 24: 1997 09/10, 22-23, 26, 28-30.

VicRoads, 1992. Section 820, Specification for Recycled crushed concrete for pavement subbase and light duty base.

VicRoads, Australia.

Zaharieva, R., Buyle-Bodin, F., Skoczylas, F.and Wirquin, E., 2002. Assessment of the surface permeation properties of recycled aggregate concrete: Cement and Concrete Composites 25: 223-232, 2003. 
FIGURES AND TABLES

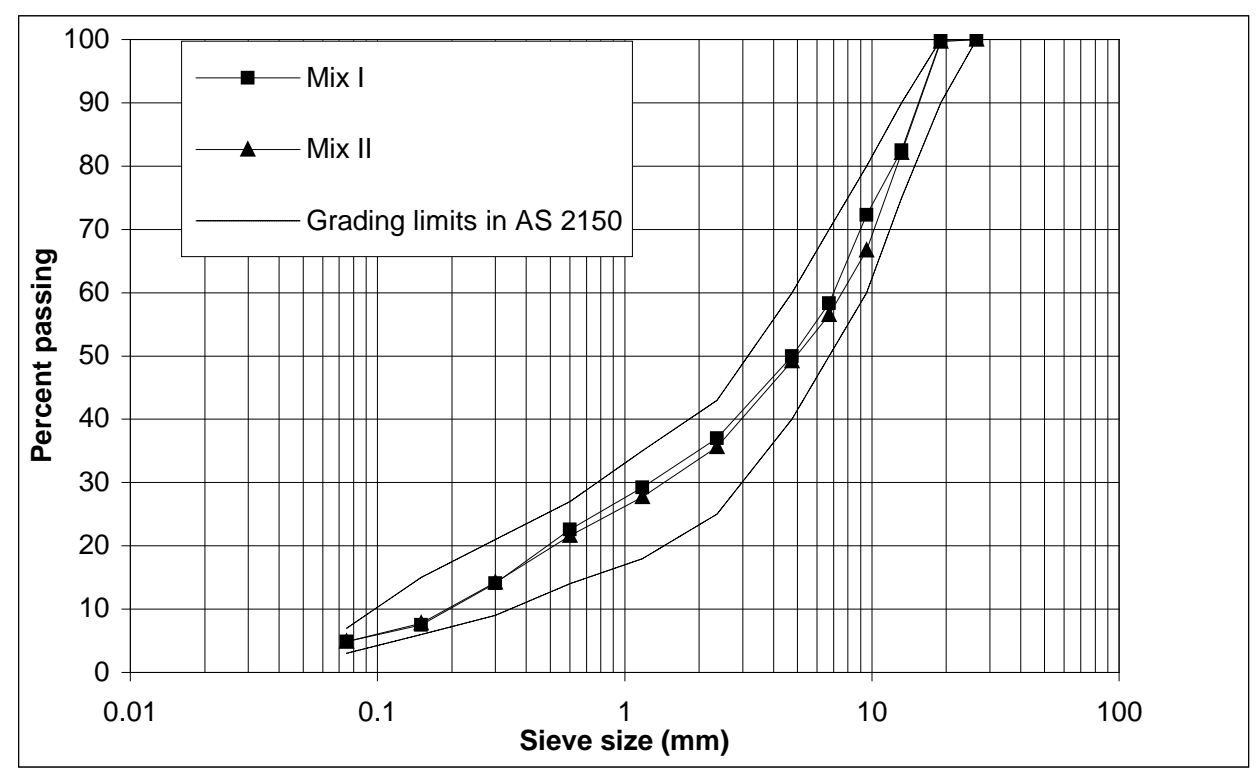

Figure 1: Particle size distribution for Mix I and II

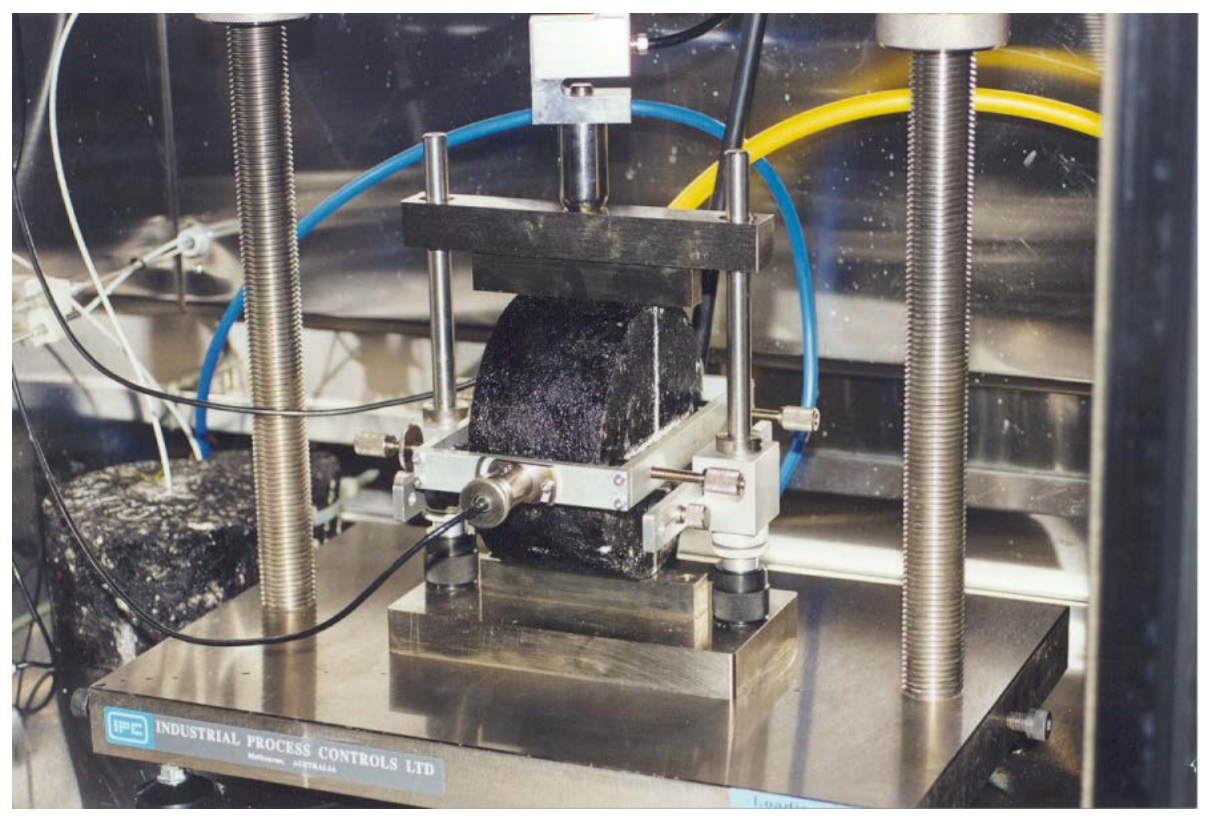

Figure 2: Resilient modulus test 


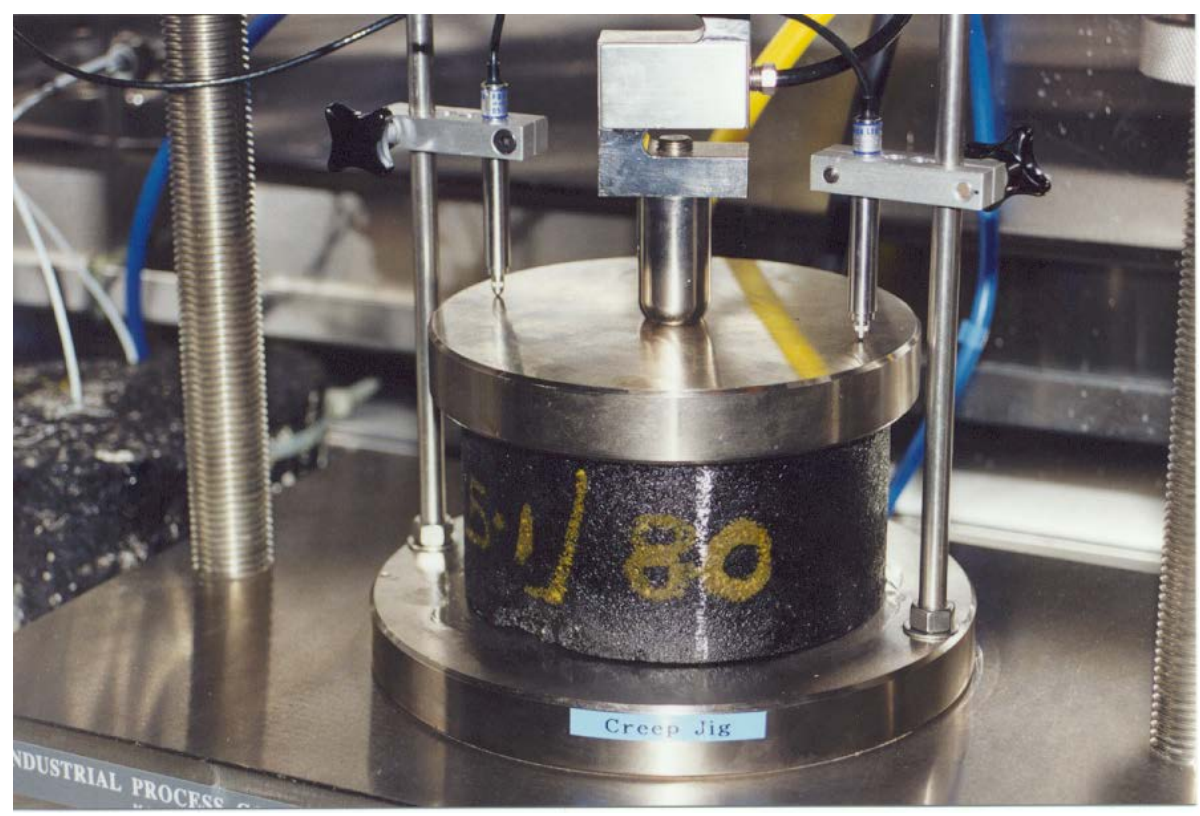

Figure 3: Creep test

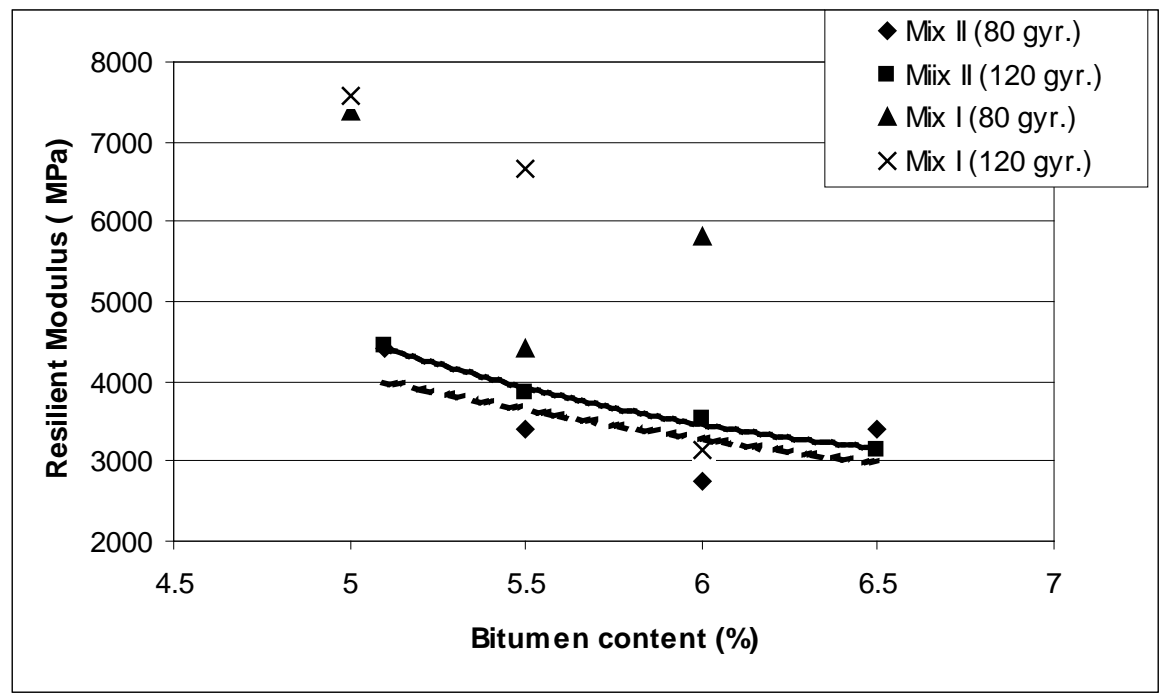

Figure 4: Effect of bitumen content and compaction effort on resilient modulus of Mix II containing RCA as coarse aggregates and Mix I containing fresh aggregates 


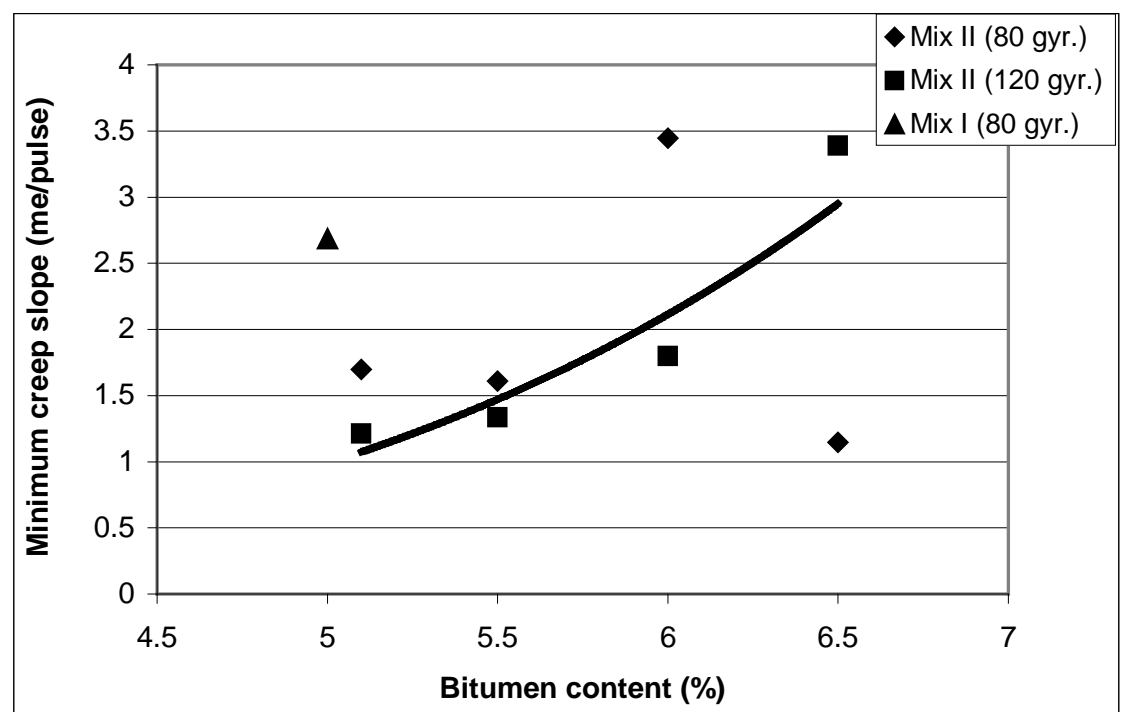

Figure 5: Effect of bitumen content and compaction effort on creep of Mix II containing RCA as coarse aggregates and Mix I containing fresh aggregates

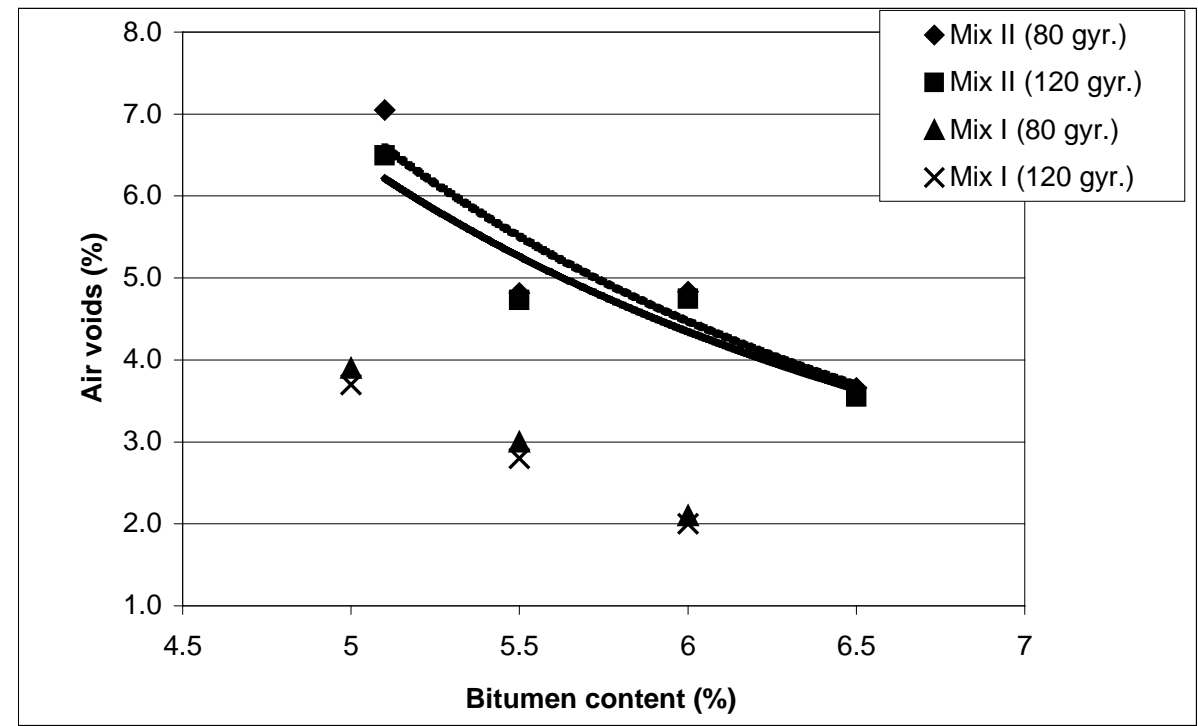

Figure 6: Effect of bitumen content and compaction effort on air voids of Mix II containing RCA as coarse aggregates and Mix I containing fresh aggregates 


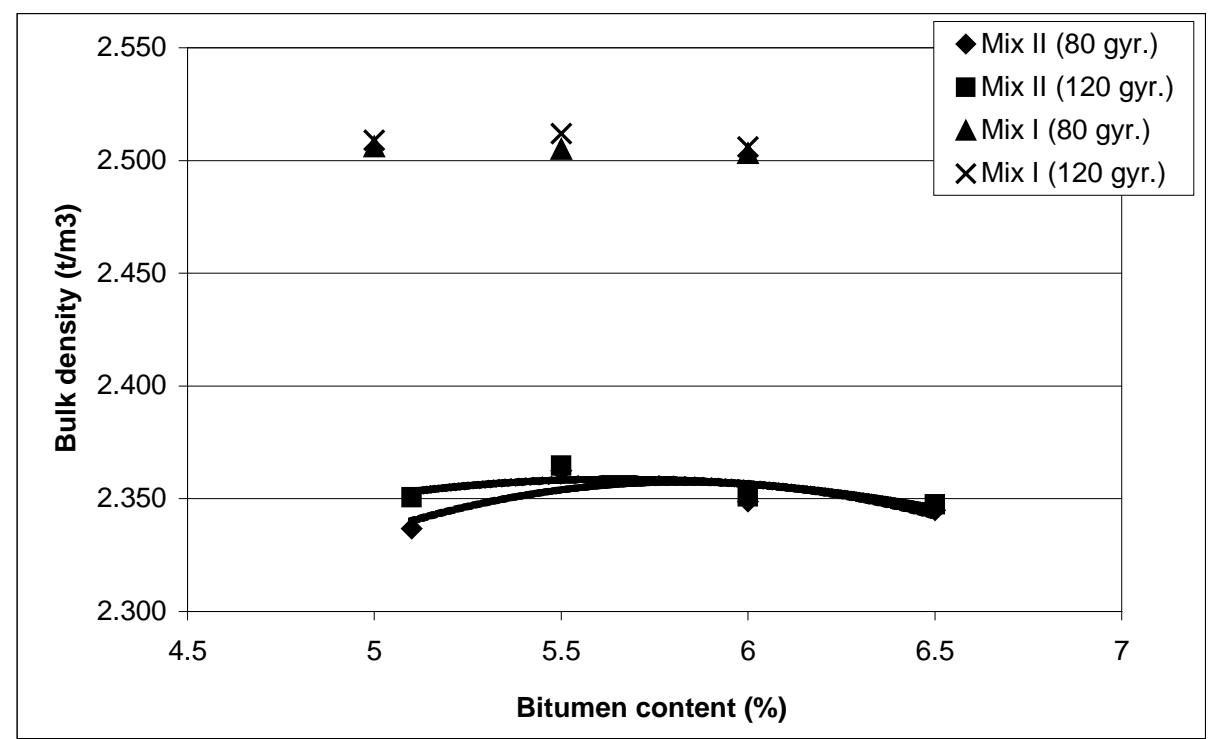

Figure 7: Effect of bitumen content and compaction effort on bulk density of Mix II containing RCA as coarse aggregates and Mix I containing fresh aggregates

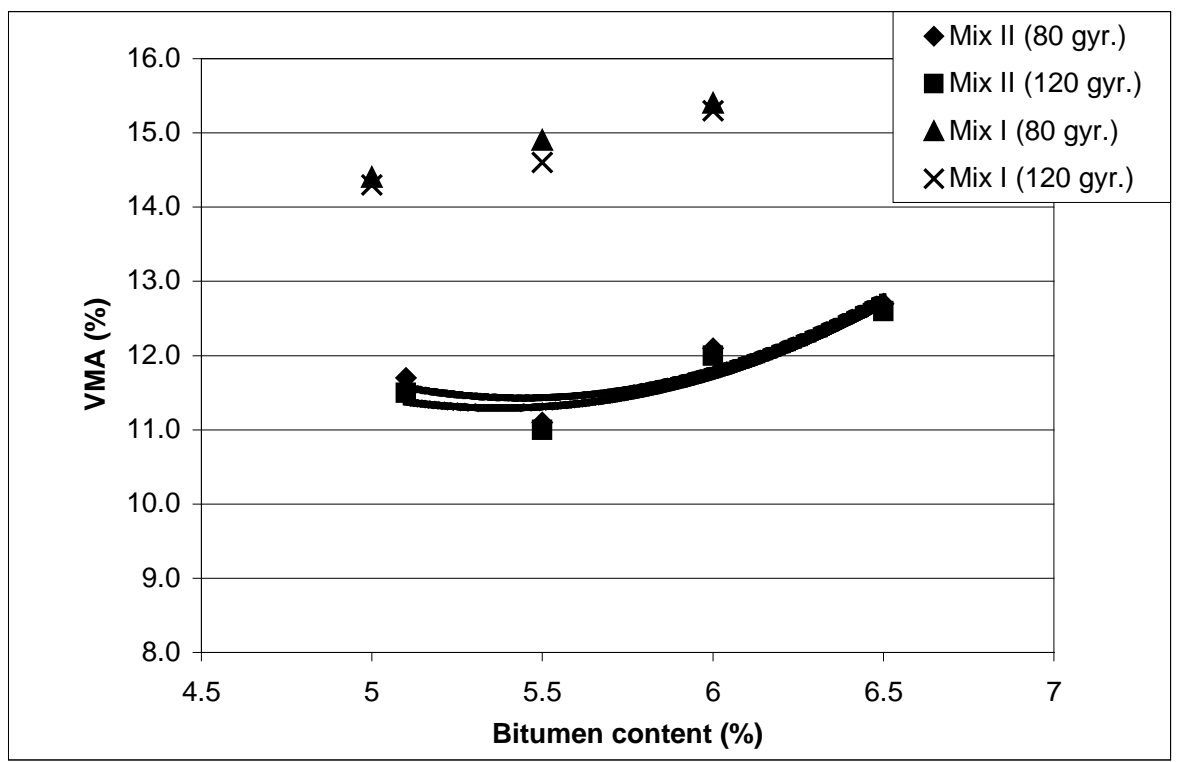

Figure 8: Effect of bitumen content and compaction effort on voids in mineral aggregates (VMA) of Mix II containing RCA as coarse aggregates and Mix I containing fresh aggregates 


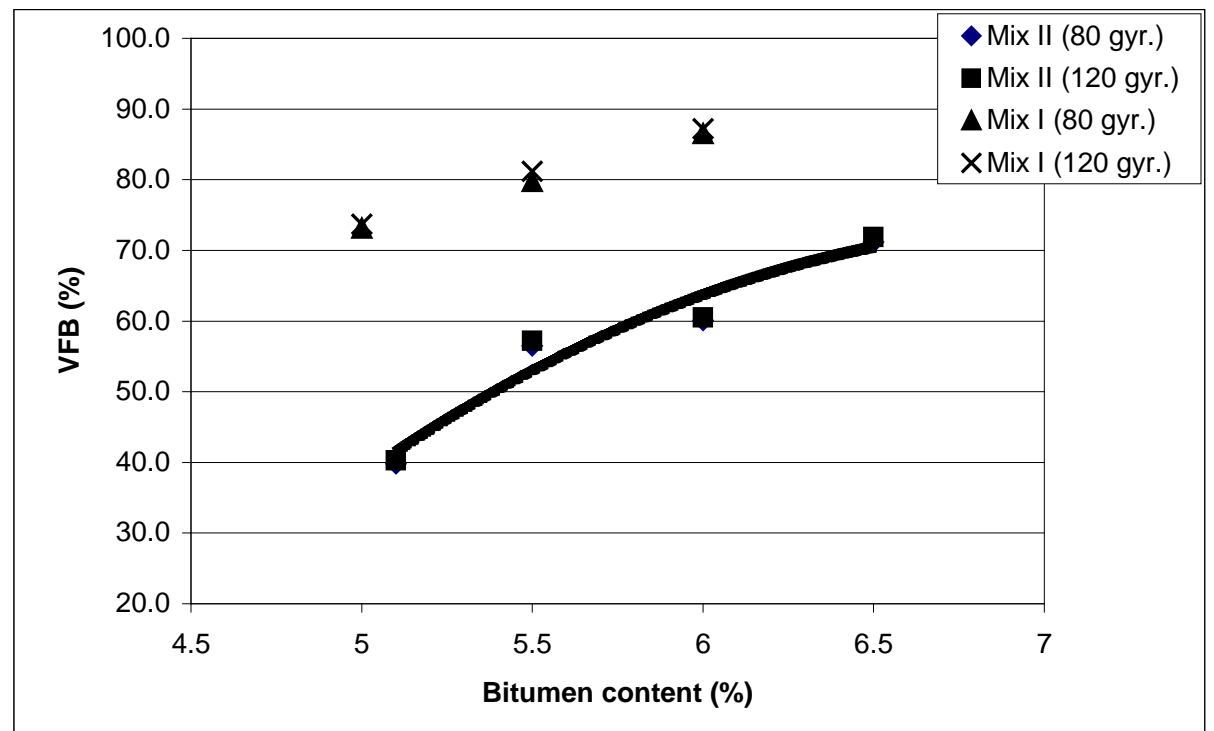

Figure 9: Effect of bitumen content and compaction effort on voids filled with bitumen (VFB) of Mix II containing RCA as coarse aggregates and Mix I containing fresh aggregates

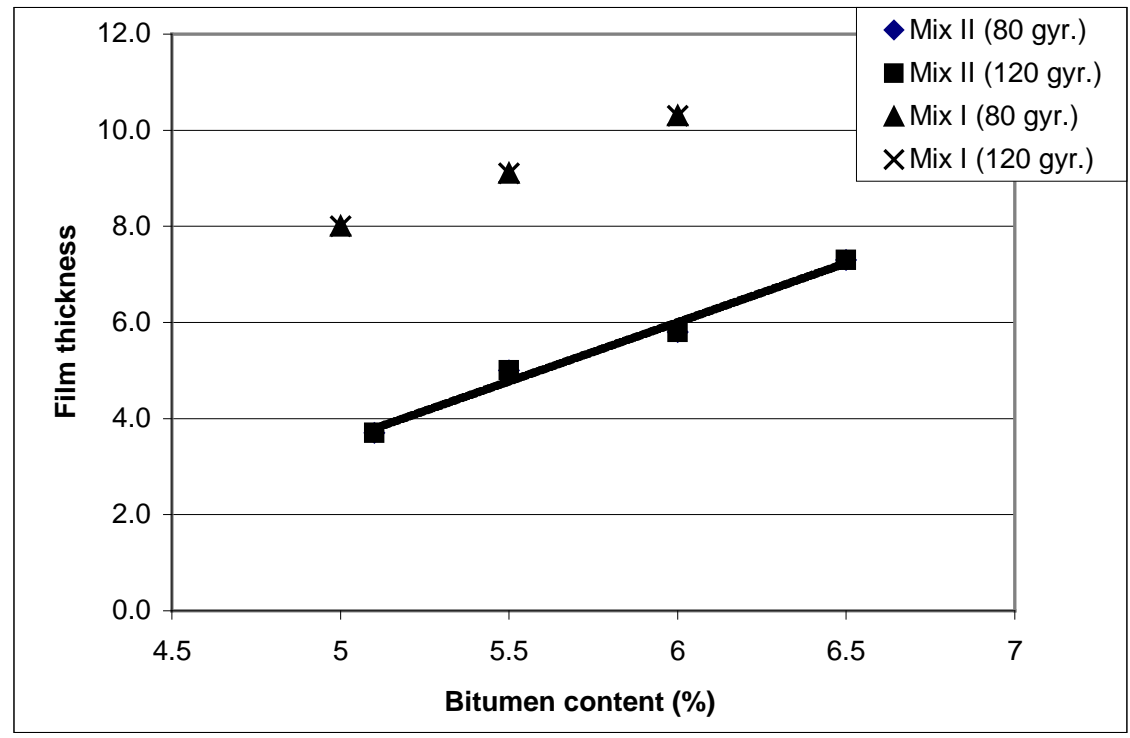

Figure 10: Effect of bitumen content and compaction effort on binder film thickness of Mix II containing RCA as coarse aggregates and Mix I containing fresh aggregates 
Table 1: Physical properties of mineral matter

\begin{tabular}{|c|c|c|c|}
\hline Type of aggregate & Physical property & Mix I & Mix II \\
\hline \multirow{4}{*}{$\begin{array}{l}\text { Coarse aggregates } \\
\text { (AS 1141.6.2-1996) }\end{array}$} & Particle density on a dry basis $\left(\mathrm{t} / \mathrm{m}^{3}\right)$ & 2.839 & 2.333 \\
\hline & $\begin{array}{l}\text { Particle density on a saturated surface dry basis } \\
\left(t / \mathrm{m}^{3}\right)\end{array}$ & 2.847 & 2.471 \\
\hline & Apparent particle density $\left(\mathrm{t} / \mathrm{m}^{3}\right)$ & 2.863 & 2.706 \\
\hline & Water absorption (\%) & 0.3 & 5.9 \\
\hline \multirow{4}{*}{$\begin{array}{l}\text { Fine aggregates } \\
\text { (AS 1141.5-1996) }\end{array}$} & Particle density on a dry basis $\left(\mathrm{t} / \mathrm{m}^{3}\right)$ & 2.701 & 2.701 \\
\hline & $\begin{array}{l}\text { Particle density on a saturated surface dry basis } \\
\left(t / m^{3}\right)\end{array}$ & 2.735 & 2.735 \\
\hline & Apparent particle density $\left(\mathrm{t} / \mathrm{m}^{3}\right)$ & 2.798 & 2.798 \\
\hline & Water absorption (\%) & 1.3 & 1.3 \\
\hline \multirow{4}{*}{$\begin{array}{l}\text { Combined aggregates } \\
\text { (AS 1141.6.2 - 1996) }\end{array}$} & Particle density on a dry basis $\left(\mathrm{t} / \mathrm{m}^{3}\right)$ & 2.779 & 2.471 \\
\hline & $\begin{array}{l}\text { Particle density on a saturated surface dry basis } \\
\left(\mathrm{t} / \mathrm{m}^{3}\right)\end{array}$ & 2.799 & 2.573 \\
\hline & Apparent particle density $\left(\mathrm{t} / \mathrm{m}^{3}\right)$ & 2.835 & 2.743 \\
\hline & Water Absorption (\%) & 0.7 & 4.0 \\
\hline
\end{tabular}


Table 2: Percent stripping and wet/dry strength variation of aggregates

\begin{tabular}{|c|c|c|c|c|}
\hline Type of aggregate & $\begin{array}{c}\text { Percent } \\
\text { stripping }\end{array}$ & $\begin{array}{c}\text { Dry strength } \\
(\mathrm{kN})\end{array}$ & $\begin{array}{c}\text { Wet strength } \\
(\mathrm{kN})\end{array}$ & $\begin{array}{c}\text { Wet/Dry strength } \\
\text { variation (\%) }\end{array}$ \\
\hline CBA* & 1 & 324 & 293 & 10 \\
\hline RCA & 12 & 128 & 85 & 34 \\
\hline AS 2758.5 limits & $10 m a x$. & Not specified & 100 min. & 35 max. \\
\hline
\end{tabular}

* CBA - crushed basalt aggregates 
Table 3: Foreign material content

\begin{tabular}{|l|c|c|}
\hline \multicolumn{1}{|c|}{ Type of particle } & $\begin{array}{c}\text { RCA } \\
(\%)\end{array}$ & $\begin{array}{c}\text { VicRoads specified limits for } \\
\text { class CC2* }\end{array}$ \\
\hline $\begin{array}{l}\text { High-density materials (metal, glass, } \\
\text { brick, asphalt, ceramics, etc.) }\end{array}$ & 1.5 & 2 \\
\hline $\begin{array}{l}\text { Low-density materials (plastic, } \\
\text { rubber etc.) }\end{array}$ & 0.1 & 0.5 \\
\hline $\begin{array}{l}\text { Wood and other vegetable or } \\
\text { decomposable matter }\end{array}$ & 0.1 & 0.1 \\
\hline
\end{tabular}


Table 4: Properties of Mix II (with RCA as coarse aggregates, 4.75-20 mm)

\begin{tabular}{|l|c|c|c|c|c|c|c|c|}
\hline Number of gyration & \multicolumn{5}{|c|}{80 gyrations } & \multicolumn{3}{c|}{120 gyrations } \\
\hline Bitumen content (\%) & 5.1 & 5.5 & 6.0 & 6.5 & 5.1 & 5.5 & 6.0 & 6.5 \\
\hline Resilient modulus (MPa) & 4424 & 3393 & 2760 & 3395 & 4445 & 3846 & 3526 & 3147 \\
\hline Minimum creep slope ( $\mu \in$ pulse) & 1.699 & 1.608 & 3.445 & 1.148 & 1.212 & 1.334 & 1.798 & 3.390 \\
\hline Air voids (\%) & 7.1 & 4.8 & 4.8 & 3.7 & 6.5 & 4.7 & 4.7 & 3.6 \\
\hline Bulk density (t/m $\left.{ }^{3}\right)$ & 2.337 & 2.362 & 2.349 & 2.345 & 2.360 & 2.365 & 2.351 & 2.348 \\
\hline Maximum density (t/m ${ }^{3}$ ) & 2.514 & 2.482 & 2.468 & 2.434 & 2.514 & 2.482 & 2.468 & 2.434 \\
\hline Voids in mineral aggregates (\%) & 11.7 & 11.1 & 12.1 & 12.7 & 11.5 & 11.0 & 12.0 & 12.6 \\
\hline Voids filled with bitumen (\%) & 39.9 & 56.5 & 60.1 & 71.2 & 40.3 & 57.2 & 60.5 & 71.9 \\
\hline Bitumen film thickness ( $\mu \mathrm{m})$ & 3.7 & 5.0 & 5.8 & 7.3 & 3.7 & 5.0 & 5.8 & 7.3 \\
\hline
\end{tabular}


Table 5: Properties of Mix I (with fresh aggregates only as control mix)

\begin{tabular}{|l|c|c|c|c|c|c|}
\hline Number of gyrations & \multicolumn{3}{|c|}{80 gyration } & \multicolumn{3}{c|}{120 gyrations } \\
\hline Bitumen content (\%) & 5.0 & 5.5 & 6.0 & 5.0 & 5.5 & 6.0 \\
\hline Resilient modulus (MPa) & 7394 & 4400 & 5807 & 7561 & 6652 & 5807 \\
\hline Minimum creep slope ( $\mu \in$ pulse) & 2.682 & $*$ & $*$ & $*$ & $*$ & $*$ \\
\hline Air voids (\%) & 3.9 & 3.0 & 2.1 & 3.7 & 2.8 & 2.0 \\
\hline Bulk density (t/m $\left.{ }^{3}\right)$ & 2.506 & 2.505 & 2.503 & 2.509 & 2.512 & 2.506 \\
\hline Maximum density (t/m $\left.{ }^{3}\right)$ & 2.607 & 2.583 & 2.556 & 2.607 & 2.583 & 2.556 \\
\hline Voids in mineral aggregates (\%) & 14.4 & 14.9 & 15.4 & 14.3 & 14.6 & 15.3 \\
\hline Voids filled with bitumen (\%) & 73.1 & 79.7 & 86.5 & 73.7 & 81.2 & 87.2 \\
\hline Bitumen film thickness ( $\mu \mathrm{m})$ & 8.0 & 9.1 & 10.3 & 8.0 & 9.1 & 10.3 \\
\hline
\end{tabular}

* creep test was conducted only for the specimen prepared at 5.0\% bitumen and 80 number of gyrations 